Article

\title{
The Impact of Pelvic Floor Muscles Exercises with and without Synergistic Muscles on Quality of Life of Women with Stage I Stress Urinary Incontinence.
}

\author{
Magdalena Ptak ${ }^{1 *}$, Agnieszka Brodowska ${ }^{2}$, Michał Ciećwież², Iwona Rotter ${ }^{1}$ \\ 1. Department of Medical Rehabilitation, Pomeranian Medical University, Szczecin, Poland \\ 2. Department of Gynecology, Endocrinology and Gynecologic Oncology, Pomeranian Medical University, Police, Poland \\ * Correspondence: magdalena.ptak@pum.edu.pl
}

\begin{abstract}
:
Stress urinary incontinence (SUI) influences the quality of life of women. The research applied ICIQ LUTS qol (The International Consultation Incontinence Questionnaire Lower Urinary Tract Symptoms quality of life) as a tool to measure the quality of life (QOL) of patients with stage 1 SUI in many areas. 140 perimenopausal women who participated in a urodynamic test at Department of Gynecology, Endocrinology and Gynecologic Oncology, Pomeranian Medical University, Police, Poland in the years 2013-2015 were enrolled in the study. Patients were divided into two groups: A and B. Two questionnaires were applied: the author's original questionnaire and the standardized ICIQ LUTS qol. Gymnastic plans were recommended 4 times per week for the period of 3 months. The plan for group A included the exercises of pelvic floor muscles (PFM) with the simultaneous tension of the transverse abdominal muscle (TrA) and for group B included the exercises of PMF without TrA. The evaluation of the quality of life of patients with stage 1 SUI with the use of ICIQ LUTS qol among patients from groups $\mathrm{A}$ and $\mathrm{B}$ after therapy showed a significant improvement in most areas. More impact is observed in the physiotherapy of both PFM with TrA.
\end{abstract}

Keywords: LUTS; stress urinary incontinence; perimenopause; pelvic floor

\section{Introduction}

The International Continence Society (ICS) defines urinary incontinence (UI) as "involuntary urination" [1, 2]. WHO puts UI in the group of social diseases, as it occurs among over $5 \%$ of the population. Depending on the cited literature, $30-60 \%$ of women in the perimenopausal and postmenopausal periods and $70-80 \%$ of women who stay at nursing homes suffer from this illness. According to a report by the World Federation of Incontinent Patients (2012), 50\% of women report cases of incontinence at some moment in their lives $[3,4]$. The highest frequency of the symptoms of $\mathrm{UI}$ is observed in the $5^{\text {th }}$ decade of a woman's life, which stands for $33 \%$ of all cases. The frequency decreases between the age of 55 to 64 and increases in the $8^{\text {th }}$ decade to $34 \%$.

The frequency of UI is not accurate because the illness is often considered as embarrassing. The patients do not always wish to inform the doctor, or they consider the problem as a natural consequence of aging [5]. However, it is certain that UI more often occurs among women (27,6\%) than men $(10,5 \%)[6]$. It is associated, among other things, with hormonal changes and the structure of the pelvic floor muscles (PFM). The dominating form of UI is stress urinary incontinence (SUI), 
which occurs among 50\% of women with UI. Defined as an uncontrolled leak, urine occurs during such activities as coughing, sneezing, laughing, jumping, running or other types physical exertion [7]. Urinary leak appears due to a rise in the intra-abdominal pressure (IAP) while the detrusor muscle (musculus detrusor) tension is too low. In terms of size, the second group of patients includes women who suffer from a mixed form of UI - around 32\%. About $14 \%$ suffer from an urgent form of UI. Regardless of the type of UI, scientists and patients agree that the phenomenon is a medical and social problem.

Bump divides the risk factors of UI among women into predisposing, causing, promoting and decompensating. The predisposing category includes factors that are related to genetics, anatomy, collagen, culture and neurology; the causes include: natural birth, damaged muscles and/or nerves, surgeries and postradiation factors; the promoting factors are: the woman's age, environmental diseases and dementia; the decompensating factors as described by Bump are: the level of physical activity of the patient, her diet, intestine dysfunction, drug-induced factors, lower urinary tract infection, obesity, mental illnesses and menopause [8].

UI does not pose a direct threat to a woman's life, but it is a complex and inconvenient problem that affects many spheres of functioning. The differences in how patients cope with the issue pose a challenge for the researchers. The study of the functioning of patients and the influence of UI on the quality of life (QOL) should include: the mental sphere, social functions, family life, interpersonal relations, sexual contacts, professional contacts and economic aspects. The International Consultation Incontinence Questionnaire Lower Urinary Tract Symptoms quality of life (ICIQ LUTS qol) is one of the questionnaires that is used to study the QOL of patients with UI. IUGA, ICS and ICUD show that it is important for the questionnaires to apply clear and simple language so that they can be completed independently by patients of different perceptions [9]. ICIQ LUTS qol includes questions concerning the influence of UI on particular spheres of life: physical activity, social contacts, sexual contacts, the emotional state and sleep. Other questions concern some activities or feelings experienced by the patient as a result of UI: wearing pads, control over liquid consumption, the change of wet underwear, anxiety connected with the unpleasant smell. The answer to the questions is included on a scale of 1-4: never or not at all (1 pt.), a bit or sometimes (2 pt.), often or moderately ( 3 pt.) and a lot or all the time (4 pt.). The patient receives a total score ranging from 19 to 76 points. ICIQ LUTS qol is a questionnaire which was formed on the basis of KHQ [10, 11].

ICS [12], IUGA [13], PTG, PTUG [14], WHO, European Association of Urology (EAU) and American College of Physicians (ACP) all recommend physiotherapeutic activities as the first thing in the treatment of UI. Another recommended course of action is counselling regarding lifestyle, urination with specific time intervals, behavioural therapy, pharmacotherapy and surgical treatment. Physiotherapeutic activities involve physical therapy (electrostimulation, magnetic stimulation) and kinesitherapy - various forms of gymnastics aimed at pelvic floor muscles. Pelvic floor muscles' exercises, which have been known for 6000 years and which have been propagated by Morris and Kegel since the second half of the $20^{\text {th }}$ century, have not been properly systematized yet. There are numerous essays, descriptions and summaries that most often lead to a conclusion that, in relation to the physiotherapy of PFM, there is no unified system of treatment, procedures or methods of verifying the results. Two biological theories define the mechanism of PFM exercises which may decrease the problem with UI. The first one is associated with the squeezing of the urethra by the external sphincter muscle of urethra (musculus sphincter urethral externus). The second theory points to the support of the bladder neck through developed, efficient muscles.

In 1988, Delancey [15] confirmed that the total tensioning of PFM leads to a rise in this layer of muscles and internal organs of the lesser pelvis in the cephalad and ventral directions, which has an influence on the correct arrangement of the urethra and on the increase of the urethral pressure. This, in consequence, prevents the leak of urine. These results have been confirmed by Kari Bø [16] in 2001 and by Thompson [17] in 2003 by means of ultrasonography and magnetic resonance imaging. Miller [18] named the balance between PFM tension and the arrangement of the urethra before coughing "the Knack manoeuvre". It is recommended in the exercise sets performed by patients [19]. Studies show that it reduces the incidents of urine leaks in SUI as early as one week after exercising. The 
mechanism of natural defence against urine leaks which appears among healthy women [20] is based on the initiation of earlier tension reflex of PFM preceding intra-bladder pressure by 200-240 ms. The Knack manoeuvre is an attempt to reconstruct this natural reflex.

DeLancey's second theory [21], which explains the effect of the reduction of the episodes of SUI by performing PFM exercises, has been functioning in literature since 1988. Kari Bø suggested that an intensive training of this layer of muscles causes mass build-up and, in consequence, forms a constant support for the organs within the lesser pelvis [22]. One of the recent studies confirming this hypothesis was published in 2012 by Pontbriand-Drolet [23]. Dynamometric measurement of the strength of PFM show that women with SUI have a lower resting muscle tone of PFM, lower maximum strength, lower contraction speed and lower endurance of PFM than healthy women $[23,24]$.

There is no doubt that it is always better to perform PFM exercises than to give up conservative treatment [25]. The studies also point to the fact that relatively better effects are caused by PFM exercises performed individually with a physiotherapist than group exercises. It has also been proven that exercising with a therapist is more effective than independent exercising at home [26,27].

Pelvic floor muscles do not work independently. Depending on the level of physical exertion, their work is supported by additional synergistic muscles: abdominal muscles (musculus abdominis) and abductor muscles of the thigh (musculus adductor femoris) [28,29]. It has been observed that the gluteus maximus muscle (musculus gluteus major) also shows signs of activity during any tension of PFM. Among women without the symptoms of UI, it has been shown that PFM tension is not possible without the initiation of spontaneous activity of the internal oblique muscle (musculus internus oblique) and the transverse abdominal muscle (musculus transversus abdominis - TrA). The synergistic activity of TrA is explained by the common biomechanical and anatomical features because TrA includes fibres from the transverse perineal muscle (musculus transversus perinei). $\operatorname{Tr} A$ activation is a natural reflex to an increase in the tension of PFM. The lack of such activation was observed among women after giving birth [30]. Sapsford [31] mentions more muscles which recruit movement units during MVC. These are: the external oblique muscle (musculus externus oblique) and the rectus abdominis muscle (musculus rectus abdominis). During passive maintaining of the constant position of lumbar spine, when there was PFM tension, EMG showed the activation of RA. EO muscles were activated during flexion, whereas TrA gave the strongest response during extension. During small tension of PFM, only TrA generated additional impulses, regardless of the position of the lumbar spine. This method of functioning of the pelvic muscles acts in an opposite manner: when the patient performs an isometric tension of the abdominal muscles, EMG registers the activation of PFM, especially the pubococcygeus muscle (musculus pubococcygeus) and the external anal sphincter (musculus external anal sphincter) [32].

The aim of the study was to compare the quality of life of patients with stage 1 SUI after the application of pelvic floor muscles' gymnastics accompanied by the synergistic muscle with the gymnastics solely with isolated pelvic floor muscles during the period of 3 months. The observation of the effects of the application of these two exercise systems was to determine which of the approaches is more effective.

\section{Materials and Methods}

\subsection{Subjects}

140 patients who participated in a urodynamic test at Department of Gynecology, Endocrinology and Gynecologic Oncology, Pomeranian Medical University, Police, Poland (to 2016 Department of Gyncology and Urogynecology, Pomeranian Medical University, Police, Poland) in the years 2013-2015 were enrolled in the study. Stage 1 SUI was diagnosed on the basis of an interview carried out by means of the Gaudenz questionnaire, subject examination and a urodynamic test. Urodynamic testing was carried out by means of the Libra apparatus (date of production - 2001, Netherlands, Medical Measurement System B.V. MMS). All of the patients fulfilled the study 
inclusion criteria and none of them fulfilled the exclusion criteria. The inclusion criteria were: age 4560 year, Gaudenz questionnaire confirmed SUI I stage, urodynamic test confirmed SUI I stage and patient's treatment permission. The bioethical committee of the Pomeranian Medical University issued a permission to carry out the research - KB0012/142/13 (30.09.2013).

In order to evaluate the effectiveness of the treatment of stage 1 SUI according to IngelmanSandberg, the patients were divided into two groups: group A ( $n=70$ people), group $B(n=70$ people). Initially, two questionnaires were applied: the author's original questionnaire and the standardized ICIQ LUTS qol (International Consultation on Incontinence Modular Questionnaire - Lower Urinary Tract Symptoms quality of life), both of them in Polish versions. Subsequently, gymnastics plan A was assigned to group A and gymnastics plan B was assigned to group B. Both groups also received vaginal estrogen therapy for a period of 3 months. ICIQ LUTS qol was completed once again after 3 months.

ICIQ LUTS qol, based on The King's Health Questionnaire (KHQ), is takes into account the influence of urinary incontinence problems on the quality of life, the limitations of general, physical and mental activities, and the changes in interpersonal relations and in everyday life. It includes 19 questions with the following choices - not at all, a bit, moderately, a lot - indicating the strength of the influence of SUI on a given subject. The number of points that a person can achieve is between 19-79. The questionnaire omitted the VAS scale which describes the level of inconvenience of particular symptoms as the data available at www.iciq.net is sufficient to obtain such information. The conversion of points of ICIQ LUTS qol is carried out on the basis of the instructions provided by Keller [80], based on The King's Health Questionnaire.

The author's original questionnaire made it possible to characterize the studied group in terms of age, BMI, WHR, smoking or risk factors of SUI.

After the initial training of patients with the aim to develop a proper tension of PFM, gymnastic plans were recommended 4 times per week for the period of 3 months. The plan for group A included the exercises of pelvic floor muscles with the simultaneous tension of the transverse abdominal muscle while lying on the back with legs bent and supported by feet. The patients performed 3 series with 10 repetitions of long tensions (6-8 sec) with the strength of $60-70 \% \mathrm{MVC}$, and two series with 10 repetitions of short tensions (1-2 sec) with the strength of $30-60 \%$ MVC. The tensions were correlated with exhaling. Additionally, if necessary, the Knack manoeuvre was recommended. The plan for group B was carried out analogically with a clear instruction for the patient not to include the tension of the transverse abdominal muscle.

All patients were provided estrogen vaginally in the form of a vaginal globule with estriol, with the dose of $0,5 \mathrm{mg}$. The frequency of intake was twice per week.

\subsection{Assessments}

The features of the studied group are presented in table 1.

Table 1. The features of the studied group A and B.

\begin{tabular}{|c|c|c|c|}
\hline & Group A & Group B & $\mathrm{p}$ \\
\hline Age $(\bar{x}+\mathrm{SD}$, years $)$ & $53,1 \pm 5,5$ & $53,0 \pm 5,7$ & $0,813 *$ \\
\hline $\mathrm{BMI}\left(\bar{x}+\mathrm{SD}, \quad \mathrm{kg} / \mathrm{m}^{2}\right)$ & $27,4 \pm 4,6$ & $27,4 \pm 5,0$ & $1,0^{*}$ \\
\hline WHR $(\bar{x}+\mathrm{SD})$ & $0,88 \pm 0,1$ & $0,81 \pm 0,1$ & $<0,001^{*}$ \\
\hline city & 75,7 & 77,1 & 0,842 \\
\hline
\end{tabular}




\begin{tabular}{|c|c|c|c|c|}
\hline $\begin{array}{c}\text { Place of residence } \\
(\%)\end{array}$ & village & 24,3 & 22,9 & \\
\hline \multirow{2}{*}{$\begin{array}{c}\text { Physical activity } \\
(\%)\end{array}$} & sitting & 12,9 & 18,6 & \\
\cline { 2 - 4 } & active & 30,0 & 25,7 & \multirow{2}{*}{0,616} \\
\cline { 2 - 4 } & mixed & 57,1 & 55,7 & \multirow{2}{*}{0,09} \\
\hline \multirow{2}{*}{$\begin{array}{c}\text { Menopausal status } \\
(\%)\end{array}$} & premenopausal & 47,1 & 61,4 & \\
\cline { 2 - 4 } & postmenopausal & 52,9 & 38,6 & \multirow{2}{*}{0,8} \\
\cline { 2 - 4 } smoking (\%) & yes & 12,9 & 11,4 & \\
\cline { 2 - 4 } & no & 87,1 & 88,6 & \\
\hline
\end{tabular}

$\bar{x}$ - average, SD- standard deviation, $\mathrm{p}^{*}$ - t-Student test, $\mathrm{p}$ - Chi²Persona

As a result of the performed analysis of the studied groups, significant differences were noted between groups A and B in terms of WHR $(\mathrm{p}<0,001)$ and the chronic exertion declared by patients a factor influencing the straining of the floor of the pelvis $(p=0,044)$. No statistically significant differences were observed in relation to other data, such as: the age of the patients, BMI, place of residence, the declared lifestyle, the existence of menopause, smoking and risk factors or coexisting factors with SUI (Table 1).

\subsection{Statistical analyses}

The reliability of the applied survey methods was evaluated by calculating the Cronbach's alpha parameter, both for the response "before" and "after" treatment. Before the treatment, the Cronbach's alpha value for ICIQ LUTS qol was 0,717 , whereas after the treatment the value was 0,844 . These numbers point to a high reliability of the provided answers.

In further analysis, continuous variables were presented by means of an arithmetic mean, standard deviation, median, minimum and maximum value, and the qualitative variables through quantity and appropriate percentage (fractions). The normality of the layout of continuous variables was verified by means of the Shapiro-Wilk test. Both of the studied groups, chosen randomly, were preliminarily compared by means of the t-Student test (arithmetic mean), and Pearson's chi2 test was used for some of the qualitative parameters. The variables acquired from the surveys were analysed by means of two-way ANOVA, time (before treatment, after treatment) x group (1. type of treatment - group A, 2. type of treatment - group B), for repeated measurements. Tukey's test served as a post hoc test. Statistical significance for all tests was set at $p<0,05$. The statistical analysis was carried out by means of the Statistica kit, v. 12.0 PL, StatSoft, the USA.

\section{Results}

Before the application of the planned treatment, no statistically significant differences in terms of the QOL of women with stage 1 SUI evaluated by means of ICIQ LUTS qol were observed between the analysed groups. 
Table 2. The comparison of the results of studies carried out by means of ICIQ LUTS qol among patients from groups A and B after the application of stage 1 SUI therapy.

\begin{tabular}{|c|c|c|c|c|c|}
\hline \multirow{2}{*}{ Score } & \multicolumn{2}{|c|}{ Group A } & \multicolumn{2}{|c|}{ Group B } & \multirow{2}{*}{$\mathbf{p}$} \\
\hline & $\bar{x}$ & $\pm \mathbf{S D}$ & $\bar{x}$ & \pm SD & \\
\hline $\begin{array}{c}\text { Role } \\
\text { limitations } \\
\text { (Q3) }\end{array}$ & 18,1 & 20,0 & 30,5 & 20,1 & $<0,0001$ \\
\hline $\begin{array}{c}\text { Physical } \\
\text { limitations } \\
\text { (Q4a) }\end{array}$ & 19,5 & 15,0 & 33,6 & 21,3 & $<0,0001$ \\
\hline $\begin{array}{c}\text { Social } \\
\text { limitations } \\
\text { (Q4b) }\end{array}$ & 6,8 & 9,7 & 22,1 & 16,7 & $<0,0001$ \\
\hline $\begin{array}{c}\text { Relationships } \\
\text { limitations } \\
\text { (Q5) }\end{array}$ & 15,0 & 24,9 & 26,4 & 26,5 & 0,132 \\
\hline Emotions (Q5) & 11,4 & 14,2 & 27,9 & 20,7 & $<0,0001$ \\
\hline $\begin{array}{c}\text { Sleep/energy } \\
\text { (Q6) }\end{array}$ & 19,8 & 19,9 & 34,3 & 19,0 & $<0,0001$ \\
\hline $\begin{array}{c}\text { Severity } \\
\text { measures (Q7) }\end{array}$ & 24,3 & 17,9 & 43,0 & 17,3 & $<0,0001$ \\
\hline Shame (QW) & 14,8 & 21,0 & 31,4 & 26,6 & 0,011 \\
\hline Suma scores & 129,7 & 98,3 & 249,2 & 104,3 & $<0,0001$ \\
\hline
\end{tabular}

$\bar{x}$ - everage; SD- standard deviation; $\mathrm{p}$ - t-Student test

The evaluation of the quality of life of patients with stage 1 SUI with the use of ICIQ LUTS qol among patients from groups A and B after therapy showed a significant improvement in most areas. Bigger improvement was observed in group A, which means that gymnastics according to plan A (PFM and SM) proved to be more efficient than plan B (PFM only). The only parameter without a statistically significant difference was the limitation of interpersonal relations (Q5).

Table 3. shows ANOVA results (group x time) for all of the areas of the QOL of patients with SUI analysed by means of ICIQ LUTS qol. 
Table 3. A two-way analysis of variance (group x time) for ICIQ LUTS qol.

\begin{tabular}{|c|c|c|c|c|c|}
\hline Score & groups & $\begin{array}{c}\text { moment of ICIQ LUTS } \\
\text { qol questionnaires } \\
\text { execution }\end{array}$ & $\bar{x}$ & SEM & $\begin{array}{c}p^{\text {ANOVA }} \\
\text { and } \\
\text { post-hoc Tukey's test }\end{array}$ \\
\hline \multirow{4}{*}{$\begin{array}{c}\text { Role limitations } \\
\text { (Q3) }\end{array}$} & \multirow{2}{*}{ A } & before & 52,6 & 2,6 & $<0,0001$ \\
\hline & & after & 18,1 & 2,4 & Ab vs Aa: $p=0,0001$ \\
\hline & \multirow{2}{*}{$\mathrm{B}$} & before & 51,0 & 2,6 & $\mathrm{Bb}$ vs $\mathrm{Ba}: \mathrm{p}=0,0001$ \\
\hline & & after & 30,5 & 2,4 & Aa vs Ba: $p=0,002$ \\
\hline \multirow{4}{*}{$\begin{array}{c}\text { Physical limitations } \\
\text { (Q4a) }\end{array}$} & \multirow{2}{*}{ A } & before & 56,4 & 2,8 & 0,01 \\
\hline & & after & 19,5 & 2,2 & Ab vs Aa: $p=0,0001$ \\
\hline & \multirow{2}{*}{$\mathrm{B}$} & before & 58,6 & 2,8 & $\mathrm{Bb}$ vs $\mathrm{Ba}: \mathrm{p}=0,0001$ \\
\hline & & after & 33,6 & 2,2 & Aa vs Ba: $p=0,903$ \\
\hline \multirow{4}{*}{$\begin{array}{c}\text { Social limitations } \\
\text { (Q4b) }\end{array}$} & \multirow{2}{*}{ A } & before & 24,8 & 2,3 & $<0,0001$ \\
\hline & & after & 6,8 & 1,6 & Ab vs Aa: $p<0,0001$ \\
\hline & \multirow{2}{*}{$\mathrm{B}$} & before & 29,5 & 2,3 & $\mathrm{Bb}$ vs $\mathrm{Ba}: \mathrm{p}<0,0001$ \\
\hline & & after & 22,1 & 1,6 & Aa vs $B a: p=0,0160$ \\
\hline \multirow{4}{*}{$\begin{array}{c}\text { Relationships } \\
\text { limitations (Q5) }\end{array}$} & \multirow{2}{*}{ A } & before & 30,0 & 3,3 & 0,126 \\
\hline & & after & 15,0 & 3,1 & Ab vs Aa: $p=0,0002$ \\
\hline & \multirow{2}{*}{$\mathrm{B}$} & before & 31,4 & 3,3 & $\mathrm{Bb}$ vs $\mathrm{Ba}: \mathrm{p}=0,515$ \\
\hline & & after & 26,4 & 3,1 & Aa vs Ba: $p=0,057$ \\
\hline \multirow{4}{*}{ Emotions (Q6) } & \multirow{2}{*}{ A } & before & 38,3 & 2,4 & $<0,0001$ \\
\hline & & after & 11,4 & 2,1 & Ab vs Aa: $p<0,0001$ \\
\hline & \multirow{2}{*}{ B } & before & 39,0 & 2,4 & Bb vs $\mathrm{Ba}: \mathrm{p}<0,0001$ \\
\hline & & after & 27,9 & 2,1 & Aa vs Ba: $\mathrm{p}<0,0001$ \\
\hline
\end{tabular}


8 of 17

\begin{tabular}{|c|c|c|c|c|c|}
\hline \multirow{4}{*}{ Sleep/energy (Q7) } & \multirow{2}{*}{ A } & before & 41,2 & 3,0 & 0,052 \\
\hline & & after & 19,8 & 2,3 & $\mathrm{Ab}$ vs $\mathrm{Aa}: \mathrm{p}<0,0001$ \\
\hline & \multirow{2}{*}{ B } & before & 47,4 & 3,0 & $\mathrm{Bb}$ vs $\mathrm{Ba}: \mathrm{p}<0,0001$ \\
\hline & & after & 34,3 & 2,3 & Aa vs Ba: $p=0,0007$ \\
\hline \multirow{4}{*}{$\begin{array}{c}\text { Severity measures } \\
\text { (Q8) }\end{array}$} & \multirow{2}{*}{$\mathrm{A}$} & before & 56,6 & 2,6 & $<0,0001$ \\
\hline & & after & 24,3 & 2,1 & Ab vs Aa: $p<0,0001$ \\
\hline & \multirow{2}{*}{ B } & before & 55,8 & 2,6 & $\mathrm{Bb}$ vs $\mathrm{Ba}: \mathrm{p}<0,0001$ \\
\hline & & after & 43,0 & 2,1 & Aa vs $\mathrm{Ba}: \mathrm{p}<0,0001$ \\
\hline \multirow{4}{*}{ Shame (QW) } & \multirow{2}{*}{ A } & before & 38,1 & 3,7 & 0,0001 \\
\hline & & after & 14,8 & 2,9 & $\mathrm{Ab}$ vs $\mathrm{Aa}: \mathrm{p}=0,0001$ \\
\hline & \multirow{2}{*}{ B } & before & 37,6 & 3,7 & Bb vs $B a: p=0,058$ \\
\hline & & after & 31,4 & 2,9 & Aa vs Ba: $p=0,002$ \\
\hline \multirow{4}{*}{ Suma scores } & \multirow{2}{*}{ A } & before & 337,9 & 11,6 & $<0,0001$ \\
\hline & & after & 129,7 & 10,6 & Ab vs $\mathrm{Aa}: \mathrm{p}<0,0001$ \\
\hline & \multirow{2}{*}{$\mathrm{B}$} & before & 350,2 & 11,6 & $\mathrm{Bb}$ vs $\mathrm{Ba}: \mathrm{p}<0,0001$ \\
\hline & & after & 249,2 & 10,6 & Aa vs $\mathrm{Ba}: \mathrm{p}<0,0001$ \\
\hline
\end{tabular}

"moment of ICIQ LUTS qol questionnaires execution": before gymnastic, after gymnastic; $\bar{x}-$ average; SEM- standard error of the mean; Ab- scores before gymnastic in A group; Aa- scores after gymnastic in A group; Bb- scores before gymnastic in B group; Ba- scores after gymnastic in B group

\section{Discussion}

Stress urinary incontinence influences the QOL of women. The research applied ICIQ LUTS qol as a tool to measure the quality of life (QOL) of patients with stage $1 \mathrm{SUI}$ in many areas. The patients underwent conservative treatment in two plans: for group A (pelvic floor muscles exercises and synergistic muscle exercises - PFM and SM) and group B (exercises with isolated pelvic floor muscles - PFM).

Basing on the results acquired from the QOL test of women with stage 1 SUI, it was observed that QOL significantly improved in most of the studied areas in both groups after performing gymnastics according to plans A and B. It has to be pointed out that both the gymnastics of pelvic 
floor muscles with the transverse abdominal muscle (plan A) and the gymnastics of isolated pelvic floor muscles (plan B) are effective after three months of exercising. It was observed that PFM and SM gymnastics (plan A) is statistically significantly more effective than sole PFM gymnastics (plan B).

Because studies based on ICIQ LUTS qol were not found in the available literature, the review of literature was performed by means of a different questionnaire - KHQ (the King's Health Questionnaire). KHQ is described as the basis for ICIQ LUTS qol and it contains mostly analogical questions [33, 34].

A detailed data analysis revealed that the influence of SUI on performing housework such as cleaning, shopping, professional work and simple activities away from home (Q3) decreased significantly in both of the studied groups. The conservative treatment yielded good results regardless of the chosen gymnastics plan. Similar results were achieved by Fitz et al. [35] who studied the QOL among 36 women aged 55,2 \pm 9 before and after the application of PFM gymnastics. All study areas of QOL showed statistically significant improvement. In that research, gymnastics included only PFM. Similarly, the effectiveness of this type of gymnastics was confirmed by the results presented by Rett et al. [36]. An improvement was observed as early as after the $6^{\text {th }}$ week of treatment. Additionally, the applied biofeedback (EMG) method improved the effects of the treatment. The method was also applied in a research by Hirakawa et al. [37], which compared normal PFM exercises with PFM exercises accompanied by biofeedback. 46 women were studied and every one of them confirmed that there was a positive influence of exercises and exercises accompanied by biofeedback. A significant difference was observed. The biofeedback method was also applied in studies by the Capellini team [38]. For 12 of the patients, gymnastics were recommended in the form of 30-40 minute sessions performed twice a week in a lying position, accompanied by surface EMG, 3 series with 10 repetitions. The sessions were gradually expanded. From week 1 to week 4 , they included 5 seconds of tension and 10 seconds of relaxation (5/10); from week 5 to week 8 -10/10; from week 9 to week $12-20 / 20$. According to the patients, this method resulted in a significant decrease of role limitations. Pereira et al. [39], while observing the differences in evaluation of the QOL of women with SUI, compared group and individual exercises with a control group. There were significant differences which proved that PFM (only) gymnastics carried out for a period of 6 weeks positively influenced the areas of household and professional activity of the studied women. Analogical results were achieved in the study by Balmforth et al [40] in which the patients performed intensive PFM training for a period of 14 weeks. Despite the fact that in Nascimento-

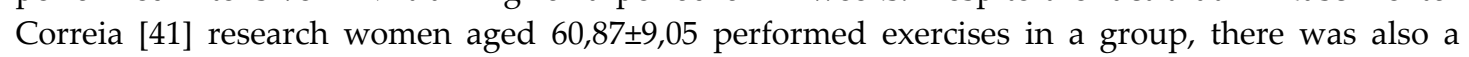
statistically significant difference in the evaluation of QOL in these areas. The exercises were performed during a period of 12 weeks, for 1 hour, while lying on back and sitting on a chair.

Interesting relations were noticed by Nelas et al. [42] while studying QOL and the sensitivity to stress resulting from UI among women aged $58,42 \pm 11,52$. An interesting difference in the perception of the limitations of social roles caused by problems with the bladder was observed among women aged 57-58. Older women performed better in this area. Their results were negatively correlated with perfectionism and stress sensitivity.

In the studies by Lacombe et al. [43] one can observe an original approach to PFM tension, unseen in any other plan. The method is considered by the authors' as their own creation. It is based on requesting from the patient the tension of muscles of the perineum (the forward part) while setting the body to lying on back, with lower limbs bent in hip and knee joints at $90^{\circ}$ and to perform the tension while exhaling and pulling the lower limbs towards the chest using the upper limbs to set the lower limbs in a "frog's" position (pulling knees away and joining feet together). Such exercises were recommended daily for a period of one year. The participants of the study included 20 women aged 35-60 who showed a significant improvement in area Q3.

The analysis of literature concerning the influence of PFM and SM exercises on household chores, professional activities and other activities away from home revealed that so far no research in this field has been carried out among women with stage 1 SUI. 
SUI is an illness which negatively influences the level of physical activity and travelling. An increase of the intra-abdominal pressure (IAP) occurs during running, jumping and going upstairs or downstairs. In QOL research, women point this out as a significant functioning limitation $[44,45,46]$. On the basis of the results, it was proven that among the studied women with stage 1 SUI, a significant difference was also noted in area Q4a, i.e., physical limitations, which included sport (walking, running, gymnastics) and travelling. Studies confirmed that the application of PFM gymnastics in SUI improves the QOL of patients, regardless of the proposed plan. However, better results were achieved in the group that exercised using PFM and SM.

Similar results to the ones found in this study were achieved in the research carried out by Fitz et al. [35], with the application of PFM exercises as conservative treatment among women with SUI through a period of 3 months. Rett et al. [36] also observed a significant change in the evaluation of the influence of urinary incontinence on the physical activity of women after conservative treatment. The applied method of gymnastics included PFM only. The duration of the whole research was 6 weeks and it was divided into two individual meetings per week which lasted for 45 min and were accompanied by sEMG. Maybe the additional sight stimulation - the observation of work of one's own muscles - caused the effect of improvement after 6 weeks. The observation of muscle work for twice the amount of time than mentioned before was applied by Hirakawa et al. [37]. The comparison of the PFM group and PFM biofeedback group showed a significant difference in the evaluation of QOL regarding the physical activity of both groups. The effectiveness of the biofeedback method which accompanied PFM exercises was also confirmed by Capellini et al. [38] through a differentiated gymnastics program which lasted 12 weeks. The difference in the evaluation of physical limitations was significant for these patients. Individual exercises with a therapist carried out in the study by Pereira et al. [39] lead to a significant improvement of the evaluation of the influence physical activity on SUI. Conservative treatment was carried out for 1 hour per session, twice a week, for a period 6 weeks. The individual, intensive gymnastics, carried out for 14 weeks, recommended by Balmforth et al. [40] to 97 women with SUI also yielded positive results in this field of QOL. The patients reported an improvement in terms of the ability to perform duties at home and at work. In the study by Lacombe et al. [43], in which the author's original method of PFM exercising was applied, significant differences were observed as well. Such results were not achieved in the NascimentoCorreia research [41]. Group exercises did not have a statistically significant influence on the improvement of QOL.

According to the results, in reference to the area studying the influence of SUI on the limitations in human relations or meeting/visiting friends and the limitations of family life (Q4b), gymnastics based on plans A and B significantly positively influences this area. By reviewing the available literature different conclusions can be found in the research by Pereira [39]. Individual treatment applied in a group of 17 women did not show significant changes in their evaluation. It is possible that the treatment was too short (6 weeks) for the patients to experience any improvement. Even though the training of women in the Nascimento-Correia et al. research [41] was carried out for a period of 12 months, there were also no statistically significant results in terms of the evaluation of this area of life before and after the applied treatment. The research by Hirakawa et al. [37] partially confirmed the earlier results. In the comparison between PFM and PFM biofeedback groups it was proven that only with the support of muscle work visualisation a positive effect can be achieved. Significance was proven in the group that exercised with this method. A change was also observed by the Capellini team [38], in which case the work visualisation PFM method was applied. Other results were achieved in the research by Rett et al. [36] who, in the case of SUI patients, recommended exercising for a period of 6 weeks (twice a week, each session for $45 \mathrm{~min}$ ). After this time, a significant improvement was observed among 26 of the studied women. It is possible that the results of the treatment were associated with a high number of repetitions (200) of PFM contraction and the use of biofeedback. Similar results were achieved by Fitz et al. [35]. The team carried out the treatment for 12 weeks and also achieved a significant improvement in this area of QOL. The protocol of this training included 10 slow PFM contractions (6-8 sec) and 3-4 fast contractions performed while lying on back, sitting and standing. Significant results were achieved in a group of women in the research 
by Balmforth et al. [40]. An improvement was achieved in the area referring to contacts with other people, friends and family life. A significant change was also reported by 20 women who underwent conservative treatment for a period of 12 months. Research by Lacombe et al. [43] proved a significant difference in experiencing social limitations in the area using an original gymnastics method. The research by Nelas et al. [42] shows that the studied area of quality of life concerning interpersonal contacts is strongly associated with perfectionism, egocentrism and general sensitivity to stress.

A general analysis of results has showed that in terms of questions about the relations with a partner and the sexual life of patients (Q5), there are no statistically significant differences in the evaluation of the effects of treatment. However, after performing a detailed analysis (post hoc Tukey), it was proven that the differences are significant for both plans, A and B. Similar conclusions were reached by Fitz et al. [35]. No significant differences were observed despite the fact that the research was carried out for 3 months under the supervision of a qualified urogynecological physiotherapist. It has to be pointed out that the exercises involved only the PFM group. Similar results of conservative treatment were also achieved in the research by Rett et al [36] - there was no significant difference. PFM gymnastics did not significantly improve the interpersonal relations among patients with SUI. By comparing PFM gymnastics carried out in a group system and individual training with a control group Pereira et al. [39] also did not prove any significance. The reason for the lack of any clear improvement in this area may be the case of sexual life of patients, which is inquired (Q5) by ICIQ LUTS qol. No significant results that would imply successful treatment and the possibility of influencing QOL were observed in the research by Nascimento-Correia et al. [41] and Balmforth et al. [40]. The PFM area directly taking part in a sexual act does not work properly among SUI patients. Patients are not only afraid of an improper smell during UI, but they are also embarrassed by the possibility of leaking urine during an orgasm [45]. Proper functioning pelvic floor is associated with higher sexual activity [47]. It is probable that the lack of statistically important changes in this area is associated with a deeply rooted fear of leaking urine, which was virtually eliminated in the physical sphere, but still was not changed in terms of the emotions of patients. It should be assumed that the patients need more time for emotional changes.

Lacombe et al. [43], who applied gymnastics according to an original plan for 12 months, did not observe any significant changes in the area of interpersonal relations, partner relations or sexual life. However, Hirakawa et al. [37], who did not achieve statistical significance in a group of women training PFM twice a day, every day, for 12 weeks, did observe statistical significance in a group that practised the same exercises but under the control of a biofeedback apparatus. It is possible that the women achieved a higher level of confidence of the capabilities of their lesser pelvis floor. A statistically significant positive change of interpersonal relations was also registered by Capellini et al. [38]. In this case, PFM gymnastics with sEMG biofeedback was recommended for a period of 12 weeks.

In the $\mathbf{Q 6}$ area which includes questions about the emotions associated with the influence of SUI on QOL, the following factors were evaluated: the occurrence of a gloomy mood, anxiety and stress or low self-esteem. Significant differences were observed between the reports of patients from groups $\mathrm{A}$ and $\mathrm{B}$ who underwent QOL evaluation before and after conservative treatment. Significantly higher effectiveness of plan A gymnastics (PFM and SM) was observed. The emotions that accompany patients with UI influence their QOL. As provided by Coyne et al. [48,49], there are no significant differences regardless of the type of UI, but the illness is a big psychological burden for the patient and sometimes leads to depression. Patients with UI suffer from a depression three times more often than people who do not have problem with the lower urinary tract [184]. In all of the studies mentioned before, Fitz [35], Pereira [39] and Rett [36], the patients showed a significant improvement in terms of the negative emotions which occur due to SUI. The improvement in the aforementioned studies occurred after 6 and 12 weeks of conservative treatment, when the exercises were performed only with PFM. Statistically significant differences were also achieved in individual intensive exercises carried out for a period of 14 weeks in a group of SUI patients in the research by Balmforth et al. [40]. Moreover, statistical significance was also confirmed in both of the studied groups in the research by Hirakawa et al. [37]. Such emotions as sadness, anxiety, nervousness or low 
self-esteem associated with SUI differed after 12 weeks of PFM and PFM biofeedback gymnastics. Statistically significant results in reference to the benefits of PFM biofeedback gymnastics were also achieved by Capellini et al. [38]. The patients trained on the basis of the developed plan (mentioned earlier) for a period of 12 weeks. The research by Lacombe et al. [43] also confirmed the effectiveness of PFM gymnastics, recommended for a period of 12 months. The exercises were carried out according to an original plan. In the research by Nelas [42], the emotional side of SUI was negatively correlated with the perfectionism of the patients, their emotional blocks or inhibitions, the lack of support or the susceptibility to stress. In the Nascimento-Correia et al. research [41], no significant differences were achieved in terms of the changes of QOL of women who trained 1-hour group gymnastics for 12 months.

In the area of QOL concerning the influence of the symptoms of SUI on sleep, tiredness and exhaustion (Q7), a statistically significant improvement was observed in relation to the effectiveness of both plans (A and B). Furthermore, the superiority of plan A (PFM and SM) over plan B (PFM) was confirmed in terms of effectiveness. A statistically significant improvement was observed in the research by Fitz et al., which included conservative treatment for a period of 3 months, 3 times a week. The study by Rett et al. [36] also points to an emotional improvement in reference to SUI. The scientists also applied sole PFM gymnastics, twice a week, for a period of 12 weeks, in the form of individual sessions with a therapist. In the SUI therapy designed by Nascimento-Correia et al. [41] in which the patients participated in group exercises for 12 sessions (1h per week), a significant difference was observed. The patients experienced smaller changes in the excess or insufficiency of energy. Similar results were achieved by Balmforth et al. [40] who carried out conservative SUI treatment in the form of individual meetings with a therapist for a period of 14 weeks. A significant change was observed in the studied area after the application of gymnastics. The results of 12 week PFM gymnastics accompanied by sEMG carried out by Capellini et al. also showed significant changes in the level of energy of the patients. The research by Lacombe et al. which lasted for a period of 12 months confirmed a significant difference in the level of energy of 20 women who participated in an original programme of improving PFM. The research carried out by Pereira et al. [39] did not reveal any significance in the difference of the influence of SUI on the occurrence of exhaustion, tiredness or sleeping problems. It has to be mentioned that the conservative treatment concerned only PFM, for the period of 6 weeks, twice a week, for 1 hour. The treatment which lasted half of that time did not yield the expected results despite the fact that the real number of meetings with a therapist was similar. No significant differences were observed in the research by Hirakawa et al. [37] despite the fact that the exercises were carried out for 12 weeks, twice a day. Furthermore, the desired effects were not achieved in the second group that exercised with the biofeedback method.

The questions from the Q8 area concerned: wearing hygienic pads, controlling liquid consumption, the changing of underwear after a leak and worrying due to the unpleasant smell. The research showed statistically significant changes regarding the influence of PFM gymnastics on QOL regardless of the chosen plan and it proved that plan A (PFM and SM) is superior to plan B. Significance in this area was also achieved in the research by Fitz et al. [35]. Nelas et al. [42] observed that patients who lack support during the illness, have worse living conditions and are generally vulnerable to stress suffer more from the symptoms of SUI and they perform the aforementioned activities more intensively. While comparing group exercises with individual PFM exercises, Pereira et al. [39] observed that PFM exercises significantly influence the changes in attitude towards UI and the reduction of the control of this area. The Nascimento-Correia [41] research team also achieved similar results. Group exercises divided into 12 meetings, 1 hour each, also prove to be effective. An improvement of health was also observed in reference to 12 week PFM and PFM biofeedback exercises which were recommended in the research by Hirakawa et al. [37]. The method was also applied for a period of 12 weeks in a group of 14 patients in the research by Capellini et al. [38]. The team observed that the activities which accompany SUI such as wearing hygienic pads, liquid consumption control, changing underwear after a leak or worrying due to the unpleasant smell decreased thanks to PFM biofeedback gymnastics. The conservative treatment of SUI performed by Rett [36] also showed statistically significant differences in the changes of the behaviour of the 
patients even though the treatment lasted only for 6 weeks. It has to be mentioned that the research by Lacombe et al. [43] also points to a significant difference in the analysed area. 20 patients who also fulfilled the original programme for a period of 12 months also pointed to a significant difference. A lack of change in the frequency of activities performed during SUI was observed in the research by Balmforth et al. [40]. The exercises were carried out for 14 weeks and were based on an individual intensive programme.

An important emotional problem for SUI patients is embarrassment. In comparison to such problems as depression or a tumour, UI is considered as the most embarrassing [51]. In custom studies with the use of ICIQ LUTS qol, it was observed that patients experienced a significant improvement in terms of feeling embarrassed $(\mathbf{Q W})$ in relation to the problems with the bladder after the treatment based on plan A (PFM and SM). Statistical significance was also observed in reference to the difference between the applied plans. The final effect was significantly different. A question arises as to why PFM and SM exercises yield better results, i.e. the decrease in embarrassment is higher in comparison to sole PFM exercises. According to the research by Wan [52], which included 333 Chinese women who were analysed by means of ICIQ UI- SF, the Social Impact scale and Incontinence Quality-of-Life, the analysed quality of life was decreasing with the strengthening of symptoms and was associated with the rise of social isolation and the rise of the feeling of internalised shame. It can be concluded that in the case of the custom studies, a reverse mechanism occurred which lead the patients to the evaluation of their QOL after conservative treatment as better in terms of embarrassment because the feeling was less pronounced as was the experience of social isolation.

An overall analysis of the sum scores of ICIQ LUTS qol was also performed. The conclusion is that the application of PFM and SM gymnastics (plan A) and isolated PFM exercises (plan B) yields positive results in all areas. The results were statistically important - the QOL of the patients improved regardless of the applied method. With such an extensive and detailed questionnaire as ICIQ LUTS qol, it is not necessary to ask about the general QOL. However, such information makes it possible to compare the results with other scientists who ask a similar question. Taking into consideration the mentioned QOL and its changes after PFM exercises, numerous examples referring to general improvement should be mentioned. In the research by Farzinmehr et al. [53], the team compared the effectiveness of a vibration training and a gymnastics PFM training and their influence on SUI by performing measurements by means of the I-QOL questionnaire, the evaluation of the frequency of avoiding and limiting certain behaviours associated with SUI, the evaluation of the psychological and social changes and the strength of PFM. It was observed that QOL differed significantly in the evaluation of patients after the application of 12 week gymnastics, once a day. The recommended exercises were based on performing 3-4 series including 15-20 repetitions with 60 sec breaks between the series in the following positions: lying, sitting, standing, astride, lying back with hips raised, half squat and squat. By using the same questionnaire (I-QOL), Libergall-Wishnitzer et al. [54] observed a significant difference in the evaluation of QOL of SUI patients who were subjected to 12 week group PFM training (once a week, $30 \mathrm{~min}$ of gymnastics) and 2 additional trainings every 3 weeks. The patients performed the exercises in the following positions: sitting, lying, standing and walking. The PFM contractions that were recommended were quick, slow and of rising tension, with $10 \mathrm{sec}$ breaks and an interval of 1-2 minutes between the series. Patients were also encouraged to train at home.

Another example of the application of PFM exercises and their influence on QOL is the research by Jahromi et al. [55]. It was carried out in Canada among 50 women aged 60-74. The scientific tool for this research was the Questionnaire for Urinary Incontinence Diagnoses International Consultation on Incontinence Questionnaire (QUID ICIQ) and it was used to evaluate the QOL of SUI women. The exercises were performed 3 times a week plus one extra group training per week (45 min). Body positions when the PFM tension was near maximum were as follows: standing, sitting with lower limbs astride. The recommended repetitions were 8-12, the time of tension 6-8 sec and 3$4 \mathrm{sec}$ quick contractions at the end. The resting time was set at about $6 \mathrm{sec}$. Additionally, other abdominal exercises were performed and back exercises with music. The patients were also instructed to do exercises at home. The time of the research was 2 months. A statistically significant 
change in the QOL of patients was observed once the research was finished. PFM gymnastics proved to be an effective method of improving QOL. In the Polish study by Jurczak et al. [56], the quality of life of the exercising patients was also improved. By means of an original questionnaire, the authors evaluated the influence of PFM gymnastics on the state of being associated with the problems accompanying SUI among 30 women aged 46 $\pm 4,23$. The applied plan included 2 stages: stage 1 lasted for 4 weeks and included the training of 6 exercises (for about $30 \mathrm{~min}$ ), performed 5 times a week; stage 2 was the time for individual exercises at home according to a recommended plan which also lasted for 4 weeks (5 times a week, 30 min each training).

In the QOL research carried out by Indian scientists [57], the Patient Incontinence Impact Questionnaire (PIIQ) was used among 17 women aged 30-40. The SUI patients were divided into 2 groups that performed different exercises for 6 weeks. The first group trained abdominal muscles (musculus transversus abdominis - the aim was for the tension to influence the occurrence of PFM tension), diaphragmatic breathing and PFM exercises, with the recommendation to perform these exercises in Activities of Daily Living (ADL). The second group trained PFM in a classical manner, i.e., 8 quick tensions, 3 times a day and 8 slow tensions with 5 sec breaks , 3 times a day. This group was also informed about the necessity to initiate the so called "the Knack manoeuvre" in situations of rising pressure in the abdominal cavity (coughing, sneezing, laughing, etc.). It was observed that both gymnastic plans were effective and influenced the improvement of the QOL of patients. It was also revealed that the first plan was more effective than the second one. The research by Singh et al. confirms the research of this work. It emphasises the importance of the task of the transverse abdominal muscle (TrA) in the conservative treatment of SUI, improving the QOL of patients.

\section{Conclusions:}

The gymnastics of the pelvic floor muscles and the synergistic muscle (transversus abdominis muscle) and the gymnastics of the isolated muscles of the pelvic floor influence the improvement of the quality of life of women with stress urinary incontinence.

More impact is observed in the physiotherapy of both pelvic floor muscle and transversus abdominis muscle.

Acknowledgements: We thank the patients for their participation in the study.

Author Contributions: The research was conceived and designed by Magdalena Ptak. Samples were collected, prepared and analyzed by Magdalena Ptak under the supervision of Agnieszka Brodowska, Michał Ciećwież. Data analysis and interpretation was completed by Magdalena Ptak and supervised by Agnieszka Brodowska, Michał Ciećwież. The manuscript was drafted by Magdalena Ptak and was proofread and corrected by Iwona Rotter.

Conflict of interests: The authors declare no conflict of interest.

\section{References:}

1. Abrams P., Andersson K.E., Birder L., Brubaker 1., Cardozo L., Chapple C. at al.: 4th International Consultation on Incontinence Recommendations of the International Scientific Committee: Evaluation and Treatment of Urinary Incontinence, Pelvic Organ Prolapse and Faecal Incontinence. 2009. Dostępne: http://www.ics.org/publications/ici 4/files-book/recommendation.pdf (07.01.2016).

2. Haylen B.T., Ridder D., Freeman R.M., Steven E. Swift S.E., Bary BerghmansB., Lee J., Monga A., Petri E., Rizk D.E., Sand P.K., Schaer G.N., International Urogynecological Association; International Continence Society.: An International Urogynecological Association (IUGA)/International Continence Society (ICS) Joint Report on the Terminology for Female Pelvic Floor Dysfunction. Neurourol Urodyn. 2010;29:4-20.

3. Goode P.S., Burgio K.L., Richter H.E., Markland A.D.: Incontinence in older women. JAMA. 2010;303(21):2172-81. 
4. Abrams P., Cardozo L., Khoury S., Wien A.: Incontinence. W: Epidemiology of UI in woman. ICUD-EAU. 2013;27-43.

5. $\quad$ Resnick N.M.: Urinary incontinence. Lancet. 1995;6:94-99.

6. Rechberger T., Skorupski P.: Nietrzymanie moczu- problem medyczny, socjalny i społeczny. W: Rechberger T., Jakowicki J.A. (red.): Nietrzymanie moczu u kobiet- patologia diagnostyka, leczenie. Lublin: Wydaw. Bi Folium; 2005:29-38.

7. Abrams P., Cardozo I., Fall M., Griffiths D., Rosier P., Ulmsten U., van Kerrebroeck P., Victor A., Wein A.: Standardisation Sub-committee of the International Continence Society. The stadndarisation of terminology of lower urinary tract function. Report from the standarisation subcomittee of the International Continence Society. Neurourol Urodyn. 2002;21:167-178.

8. Bump R.C.: Discussion: Epidemiology of urinary incontinence. Urology 1997; 50:15-16.

9. Sjöström M., Umefjord G., Stenlund H., Carlbring P., Andersson G., Samuelsson E.: Internet-based treatment of stress urinary incontinence: a randomised controlled study with focus on pelvic floor muscle training. BJUI. 2013;112:362-372.

10. Abrams P., Avery K., Gardener N., Donovan J.: The International Consultation on Incontinence Modular Questionnaire: www.iciq.net. J Urol. 2006;175:1063-1066.

11. Nyström E., Sjöstrom M., Stenlund H., Samuelsson E.: ICIQ Symptom and Quality of Life Instruments Measure Clinically Relevant Improvements in Women With Stress Urinary Incontinence. Neurouro Urodyn. 2014;34:747-751.

12. Schröder A., Abrams P., Andersson K.E., Artibani W., Chapple R.C., Drake M.J., Hampel G.C., Neisius A., Tubaro A., Thüroff J.W.: Guidelines on Incontinence. EAU. Warszawa. 2010.

13. Hayelen B.T., Ridder D., Freeman R., Swift S., Berghmans B., Lee J., Monga A., Petri E., Rizk E.D., Sand P.K., Schaer G.N.: An International Urogynecological Association (IUGA)? International Continence Society (ICS) Join Report on the Terminology for Female Pelvic Floor Dysfunction. Int Urogynecol J. 2010; 29: 4-20.

14. Stanowisko Polskiego Towarzystwa Uroginekologicznego odnośnie stosowania laserów do leczenia wysiłkowego nietrzymania moczu i obniżenia narządów miednicy mniejszej. 2014; (accessed 12.01.2016.) http://ptug.pl/stanowisko-ptug-odnosniel

15. DeLancey J.O.L.: Structural aspects of urethrovesical function in the female. Neurourol Urodyn. 1988; 7: 509-519.

16. Bø K., Lilleas F., Talseth T., Hedland H.: Dynamic MRI of the pelvic floor muscles in an upright sitting position. Neurourol Urodyn. 2001; 20(2): 167-174.

17. Thompson J.A., O'Sullivan P.B.: Levator plate movement during voluntary pelvic floor muscle contraction in subjects with incontinence and prolapse: a cross-sectional study and review. Int Urogynecol J Pelvic Floor Dysfunct. 2003;14(2):84-88.

18. Miller J.M., Ashton-Miller J.A., Song Hong G., DeLancey J.O.L.: Clarification and confirmation of the effect of volitional pelvic floor muscle contraction to preempt urine loss (the knack maneuver) in stress incontinent women. Int Urogynecol J Pelvic Floor Dysfunct. 2008;19(6):773-782.

19. Ghoniem G.M., Leeuwen J.S., Elser D.M., Freeman R., Zhao Y.D., Yalcin I., Bump R.C., Duloxetine/Pelvic Floor Muscle Training Clinical Trial Group.: A randomized controlled trial of duloxetine alone, pelvic floor muscle training alone, combined treatment and no active treatment in women with stress urinary incontinence. Am J Urol. 2005; 173:1647-1653.

20. Bø K. Stein R.: Needle EMG registration of striated urethral wall and pelvic floor muscle activity patterns during cough, Valsalva, abdominal, hip adductor, and gluteal muscle contractions in nulliparous helathy females. Neurourol Urodyn. 1994; 13(1): 35-41.

21. De Lancey J.O.L.: Anatomy and mechanism of structures around the vesical neck: how vesical neck position might affects its closure. Neurourol Urodyn. 1988;7:161-162.

22. Bø K.: Pelvic floor muscle training is efective in teratment of female stress urinary incontinence, but how does it work? Int Urogynecol J Pelvic Floor Dysfunct. 2004;15: 76-84.

23. Pontbriand-Drolet S.: Étude comparative de la morphologie du plancher pelvien des femmes âgées continentes et avec incontinence urinaire. W: Pontbriand-Drolet S. Chapter 5. Université de Montréal. 2012:71-111.

24. Morin M., Burbonnais D.: Pelvic floor muscle function in continent and stress urinary incontinent women using dynamometric mesurements. Neurourol Urodyn. 2004;23(7):668-674. 
25. Dumoulin C., Hay-Smith E.J.C., Mac Habee-Seguin G.: Pelvic floor muscle training versus no treatment, or inactive control treatments, for urinary incontinence in women (Rewiev). The Cochrane Library. 2014;5.

26. Zanetti M.R.D., Castro R.A., Rotta A.L., Santos P.D., Sartori M., Girao M.J.B.C.: Impract of supervised physiotheraputic pelvic floor exercises for treating female stress urinary incontinence. Sao Paulo Med. J. 2007;125(5):265-9.

27. Bø K.: Pelvic floor muscle training in treatment of female stress urinary incontinence, pelvic organ prolapse and sexual dysfunction. World J Urol. 2012; 30:437-443.

28. Neuman P., Gill V.: Pelvic floor and abdominal muscle interaction: EMG activity and intra-abdominal pressure. Int Urogynecol J Pelvic Floor Dysfunct. 2002; 13(2):125-132.

29. Soljanik I., Jannsen U., May F., Fritsch H., Stief C.G., Wiessenbacher E.R., Friese K., Lienemann A.: Functional interactions between the fossa ischioanalis, levator ani and gluteus maximus muscles of the female pelvic floor: a prospective study in nulliparous women. Arch Gynecol Obstet. 2012;286(4):931-938.

30. Pereira L.C., Botelho S., Marques J., Amorim C.F., Lanza A.H., Palma P., Riccetto C.: Are transversus abdominis/oblique internal and pelvic floor muscles coactivated during pregnancy and postpartum? Neurourol Urodyn. 2013;32(5):416-419.

31. Sapsford R.: Rehabilitation of pelvic floor muscles utilizing trunk stabilization. Manual Therapy. 2004;9:312.

32. Sapsford R.R., Hodges P.W., Richardson C.A., Cooper D.H., Markwell S.J., Jull G.A.: Co-activation of the abdominal and pelvic floor muscles during voluntary exercises. Neurourol Urodyn. 2001;20:31-42.

33. Kelleher C.J., Cardozo L.D., Khullar V. Salvatore S.: A new questionnaire to asses the quality of life of urinary incontinent women. Br J Obstet Gyneacol. 1997;140(12): 1374-9.

34. Hebbar S., Pandey H., Chawla A.: Understanding King's Health Questionnaire (KHQ) in assesment of female urinary incontinence. Int J Res Med. Sci. 2015;3(3):531-538.

35. Fitz F.F., Costa T.F., Yamamoto D.M., Resende A.P.M., Stüpp L., Sartori M.G.F., Girao M.J.B.C., Castro R.A.: Impact of pelvic floor muscle training on the quality of life in women with urinary incontinence. Rev Assoc Med Bras. 2012;58(2):155-159.

36. Rett M.T., Simőes J.A., Herrmann V., Gurgel M.S.C., Morais S.S.: Qualidade de vida em mulheres após tratamento da incontinência urinária de esforço com fisioterapia. Rev Bras Ginecol Obstet. 2007;29:134-40.

37. Hirakawa T., Suzuki S., Kato K., Gotoh M., Yoshikawa Y.: Randomized controlled trial of pelvic floor muscle training with or without biofeedback for urinary incontinence. Interna Urogynecology Journal. August 2013; 24, (8), 1347-1354.

38. Capellini M.V., Riccetto C.L., Dambros M., Tamanini J.T., Herrmann V., Muller V.: Pelvic floor exercises with biofeedback fo stress urinary incontinence. Interantional Braz J Urol. 2006;32(4):462-469.

39. Pereira V.S., Correia G.N., Driusso P.: Individual and group pelvic floor muscle training versus no treatment in female stress urinary incontinence: a randomized controlled pilot study. Eur J Obstet Gynecol Reprod Biol. 2011;159(2):465-471.

40. Balmforth J.R., Mantle J., Bidmead J., Cardozo L.: A prospective observational trial of pelvic floor muscle training for female stress urinary incontinence. BJU Int. 2006 Oct;98(4):811-7.

41. Nascimento-Correia G., Santos-Pereira V., Tahara N., Driusso P.: Effects of pelvic floor muscle training on quality of life of a group of women with urinary incontinence: randomized controlled trial. Actas Urol Esp. 2012 Apr;36(4):216-21.

42. Nelas P., Duarte J., Dias A., Chaves C., Coutinho E., Amaral O.: Vulnerability to Stress and Quality of Life of Women with Urinary Incontinence. Procedia Soc Behav Sci. 2016;217:1118-1123.

43. Lacombe A.C., Riccobene V.M., Nogueira L.A.C.: Effectiveness of a program of therapeutic exercises on the quality of life and lumbar disability in women with Stress Urinary Incontinence. J Bodyw Mov Ther 2015;19:82-88.

44. Prażmowska B., Puto G., Gergont B.: Impact of urinary incontinence on life satisfaction among women aged 45 and over. Probl Hig Epidemiol. 2012;93(4):785-789.

45. Sinclair A.J., Ramsey I.N.: The psychosocial impact of urinary incontinence in women. The Obstetrician \& Gynaecologist. 2011;13:143-148.

46. Barnaś E., Barańska E., Gawlik B., Zych B.: Factors most significantly affecting quality of life in women with urinary incontinence. Hygeia Public Health. 2015;50(4):643-648.

47. Kanter G., Rogers R.G., Pauls R.N., Kammerer-Doak D., Thakar R.: A strong pelvic floor is associated with higher rates of sexual activity in women with pelvic floor disorders. Int Urogynecol J. 2015;26(7): 991-996. 
48. Coyne K.S., Zhou Z., Thompson C., Versi E.: The impact on health-related quality of life of stress, urge and mixed urinary incontinence. BJU Int. 2003;92:731-735.

49. Coyne K.S., Kvasz M., Ireland A.M., Milsom I., Kopp Z.S., Chapple C.R.: Urinary incontinence and its relationship to mental helath and helath-related quality of life in men and women in Sweden, the United Kingdom and the United States. Eur Urol. 2012;61:88-95.

50. Melvile J., Walker E., Katon W., Lentz G., Miller J., Fenner D.: Prevalence of comorbid psychiatric illness and its impact on symptom perception, quality of life, and functional status in women with urinary incontinence. Am J Obstet Gynaecol. 2002;187:80-7.

51. Elanskaia K., Haidvogel K., Heidinger Ch., Doefler D., Umek W., Hanzal E.: The geratest taboo: urinary incontinence as a source of shame and embarrassment. Wien Klin Wochenschr. 2011;123:607-610.

52. Wan X., Wang C., Xu D., Guan X., Sun T., Wang K.: Disease stigma and its mediating effect on the relationship between symptom severity and quality of life among community-dwelling women with stress urinary incontinence: a study from a Chinese city. J Clin Nurs. 2014;23(15-16):2170-2179.

53. Farzinmehr A., Moezy A., Koohpayehzadeh J., Kashanian M.: A Comparative Study of Whole Body Vibration Training and Pelvic Floor Muscle Training on Women's Stress Urinary Incontinence: ThreeMonth Follow- Up. J Family Reprod Health. 2015 Nov;9(4):147-54.

54. Liebergall-Wischnitzer M., Paltiel O., Hochner Celnikier D., Lavy Y., Manor O., Woloski Wruble A.C.: Sexual function and quality of life of women with stress urinary incontinence: a randomized controlled trial comparing the Paula method (circular muscle exercises) to pelvic floor muscle training (PFMT) exercises. J Sex Med. 2012 Jun;9(6):1613-23.

55. Jahromi M.K., Talebizadeh M., Mirzaei M.: The Effect of Pelvic Muscle Exercises on Urinary Incontinency and Self-Esteem of Elderly Females With Stress Urinary Incontinency, 2013. Glob J Health Sci. 2015. 7(2);7179.

56. Jurczak I., Chrzęszczyk M.: Ocena wpływu ćwiczeń mięśni dna miednicy na redukcję objawów i jakość życia kobiet z wysiłkowym nietrzymaniem moczu. Pol Med. J.2016:XL (237);168-172.

57. Nirupma S., Narayan A.K., Aisha P.: Effectiveness of Pelvic Floor (PF) Rehabilitation by Recruiting Abdominals (global) vs Kegels in the Management of Stress Urinary Incontinence in Women. Indian J. Physiother. Occup. Ther. 2016;10(3):7-11.

(C) 2017 by the authors. Licensee Preprints, Basel, Switzerland. This article is an open access article distributed under the terms and conditions of the Creative Commons by Attribution (CC-BY) license (http://creativecommons.org/licenses/by/4.0/). 